\title{
Effect of xylazine administration before laparoscopic abomasopexy to correct left displaced abomasum on markers of stress in dairy cows
}

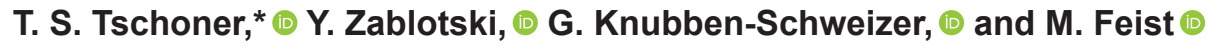 \\ Clinic for Ruminants with Ambulatory and Herd Health Services at the Centre for Clinical Veterinary Medicine, \\ Ludwig Maximilian University of Munich, Sonnenstrasse 16, 85764 Oberschleissheim, Germany
}

\begin{abstract}
Left displacement of the abomasum in dairy cows is a disease diagnosed all over the world. In Germany, a common method for its correction is laparoscopic abomasopexy (LA). The aim of the study was to assess cortisol and substance $\mathrm{P}$ concentrations, behavioral patterns, and feeding and rumination times during and after LA in cattle treated with xylazine before LA compared with nonsedated cattle. A total of 28 cattle that had been referred to a veterinary teaching hospital with a diagnosis of left displacement of the abomasum were randomly assigned to 1 of 2 groups. Surgery was performed according to a standardized protocol. Animals of XYL $(\mathrm{n}=14)$ received xylazine $(0.02 \mathrm{mg} / \mathrm{kg}$ body weight i.v.) before surgery, and animals of CON ( $\mathrm{n}=$ 14) received a placebo $(0.9 \%$ saline i.v. $)$. All cows received ketoprofen (3 $\mathrm{mg} / \mathrm{kg}$ body weight i.v.) twice, and benzyl penicillin procaine $(20,000 \mathrm{IU} / \mathrm{kg}$ body weight i.m.) for $5 \pm 1$ d. Blood samples for the determination of plasma cortisol concentration (PCC) and plasma substance $\mathrm{P}$ concentration were taken $3 \mathrm{~h}$ before surgery (+00:00), at $1100 \mathrm{~h}(+03: 00), 1115 \mathrm{~h}(+03: 15$, skin incision), $1130 \mathrm{~h}(+03: 30), 1145 \mathrm{~h}(+03: 45$, dorsal recumbency), $1200 \mathrm{~h}$ (+04:00, end of surgery), $1230 \mathrm{~h}$ $(+04: 30), 1300 \mathrm{~h}(+05: 00), 1400 \mathrm{~h}(+06: 00)$, and 1100 $\mathrm{h}(+27: 00)$ the following day. Behavior was assessed on the day of surgery and the following day $(0800,1300$, and $1700 \mathrm{~h}$ ), and during surgery. Feeding and rumination time were recorded for $24 \mathrm{~h}$ after surgery. Data analysis was done using $\mathrm{R}$ (R Foundation for Statistical Computing, Vienna, Austria). The LA was performed in all animals without negative effects. The PCC was lower in XYL than in CON at all times and significantly lower at $+03: 30$. In CON, PCC was significantly higher at +03:45, +04:00, and +04:30 compared with +03:00. In XYL, PCC was significantly lower at $+03: 15$ and
\end{abstract}

Received March 13, 2020.

Accepted May 26, 2020.

*Corresponding author: t.tschoner@lmu.de
+03:30 compared with +03:00, and significantly higher at $+04: 00$ and $+04: 30$. Plasma substance $\mathrm{P}$ concentration did not differ between groups. No differences were observed in behavior between CON and XYL. Feeding and rumination times did not differ between groups. Animals in XYL showed significantly more chews per bolus after surgery than animals in CON. In conclusion, administration of xylazine before LA results in lower stress levels for cattle during the course of LA, especially before being put into lateral and dorsal recumbency. Therefore, in the opinion of the authors, xylazine administration can be recommended before LA to improve the well-being of the animals during and after surgery.

Key words: cattle, surgery, cortisol, substance P

\section{INTRODUCTION}

Left displacement of the abomasum (LDA) is seen in cattle all over the world (Dirksen, 2006) with an incidence of 0.05 to $5.8 \%$ (Mueller, 2011). It causes huge economic losses due to decreased milk yield (Fiore et al., 2018), increased risk of culling, and prolonged interval from calving to first service (Jorritsma et al., 2008). Left displacement of the abomasum is associated with parturition, most cases can be seen within the first 4 wk after calving (Dirksen, 2006; Jorritsma et al., 2008; Fiore et al., 2018).

Different methods for the correction of LDA have been described, such as conservative treatment (rolling the animal; Mueller, 2011), closed techniques (blind tack and toggle pin), and open surgical procedures (Trent, 2017). Laparoscopic abomasopexy (LA) combines the advantages of blind toggle pin techniques (fast, minimally invasive) with the advantage of visualization of the abdominal cavity, resulting in less risk of incorrect fixation (Janowitz, 1998; Roy and Rousseau, 2017). Another benefit is the absence of the necessity of administration of antibiotics in animals without concurrent diseases, limiting the withdrawal times for milk and maintaining the option to slaughter the animal 
(Janowitz, 1998; Roy and Rousseau, 2017) as well as reducing the amount of antimicrobials that are used in farm animals. The 2-step technique, first described in 1998 (Janowitz, 1998), is the surgical technique most often used for a LA (Roy and Rousseau, 2017). The first step is performed while the animal is standing, whereas for the second step, the animal is placed in dorsal recumbency, either by casting and rolling the animal or by using a specially designed tilt table (Janowitz, 1998; Roy and Rousseau, 2017). It has been proven that putting cows in lateral recumbency using a surgical tipping table results in an increase of cortisol concentrations in the blood due to stress (Pesenhofer et al., 2006; Rizk et al., 2012a,b). Stress plays an important role concerning the welfare of cattle. The increased concern about the welfare of cattle supports the need for analgesic protocols during painful as well as stressful interventions (Huxley and Whay, 2006).

Cortisol has long been described as an indicator for stress, fear, and pain and has been reviewed extensively (Molony and Kent, 1997; McMeekan et al., 1998; Faulkner and Weary, 2000). In the last $10 \mathrm{yr}$, research has also focused on substance $\mathrm{P}(\mathbf{S P})$ as a more objective indicator for pain in cattle (Coetzee et al., 2008; Whitlock et al., 2012; Tschoner et al., 2018). However, $\mathrm{SP}$ is also found in the areas of the neuraxis, which is involved in the integration of pain, stress, and anxiety (Coetzee, 2011).

Before surgery, pre-emptive analgesia is recommended for the prevention of the onset of nociception (Otto, 2001; Anderson and Muir, 2005), but sedation is normally not performed in animals undergoing LA as described by Janowitz (1998). The administration of an $\alpha$-2-agonist (for example, xylazine) results in the reduction of stress and cortisol concentrations in animals being positioned in lateral recumbency (Rizk et al., 2012a,b), and in the inhibition of the release of norepinephrine and SP (Anderson and Muir, 2005). However, veterinarians do not use xylazine routinely during LA or laparotomy in the standing animal, mostly because of the fear of cows lying down, which interferes with the procedure and with the creation of a pneumoperitoneum (Roy and Rousseau, 2017). To our knowledge, no study has evaluated the effect of an $\alpha$-2-agonist (xylazine) on the course of LA and the concentrations of cortisol and $\mathrm{SP}$ in the blood plasma of cattle to date. The objectives of this study were to describe the changes of plasma cortisol and SP concentrations during and after LA with or without the administration of xylazine and to evaluate if there were any adverse effects on the course of the surgery, and to assess behavioral patterns as well as feeding and rumination times during and after LA.

\section{MATERIALS AND METHODS}

All experimental procedures in the present study were approved by the ethics committee of the government of Upper Bavaria (reference number 55.2-1-55-2532-1172015). Determination of sample size was done based on cortisol as the primary outcome. Sample size was determined via the $t$-test for independent samples, which compared 2 mean values. Previous studies showed that plasma cortisol is approximately normally distributed and that the biologically relevant (and expected) difference between the mean values is $15 \mathrm{nmol} / \mathrm{L}$ and that the standard deviation is approximately $13 \mathrm{nmol} / \mathrm{L}$ (Rizk et al., 2012a,b). To be able to detect an expected difference of at least $15 \mathrm{nmol} / \mathrm{L}$ in a 2-sided test with a type I error of $\alpha=0.05$ and a power of 0.80 a group size of 13 animals is necessary. Since a dropout of around $10 \%$ is expected, 1 reserve animal is required for each group. Thus, our experiment required a total of $\mathrm{n}=28$ animals, with 14 animals needed per group. Experimental setup on the day of the surgery is given in Figure 1.

\section{Animals and Group Assignment}

Twenty-eight cows of the breeds German Simmental $(\mathrm{n}=23)$, Holstein Friesian $(\mathrm{n}=4)$, and Brown Swiss $(\mathrm{n}=1)$ aged 2.9 to $11 \mathrm{yr}(6.0 \pm 2.0 \mathrm{yr})$ and with BW between 457 and $905 \mathrm{~kg}(662.3 \pm 110.7 \mathrm{~kg})$, which were presented with LDA at the Clinic for Ruminants with Ambulatory and Herd Health Services between April 1, 2016, and July 18, 2019, were included in the study. Animals had to be at least in their second lactation. Exclusion criteria were concurrent diseases that strongly impaired the general condition of the animals (sepsis, lameness score of $\geq 3$ out of 5 ; Sprecher et al., 1997), moderate to severe dehydration, diarrhea), or if the temperament of the animal did not allow the animal to be handled or moved without the need of xylazine. The study was conducted as a randomized controlled double blinded trial; the cows were randomly assigned to either the control group $(\mathbf{C O N}, \mathrm{n}=14)$ or xylazine-treated group (XYL, $\mathrm{n}=14$ ). Randomization consisted of a lottery with equal numbers of lots for CON and XYL in sealed envelopes, which were kept locked. The person performing the blood sampling and behavioral scorings did not have access to the envelopes. Before each surgery, one envelope was randomly chosen by the surgeon, and either xylazine or saline were presented in a syringe to the person performing the experiment. This person did not know the group assignment of the animals until all trials were completed. 


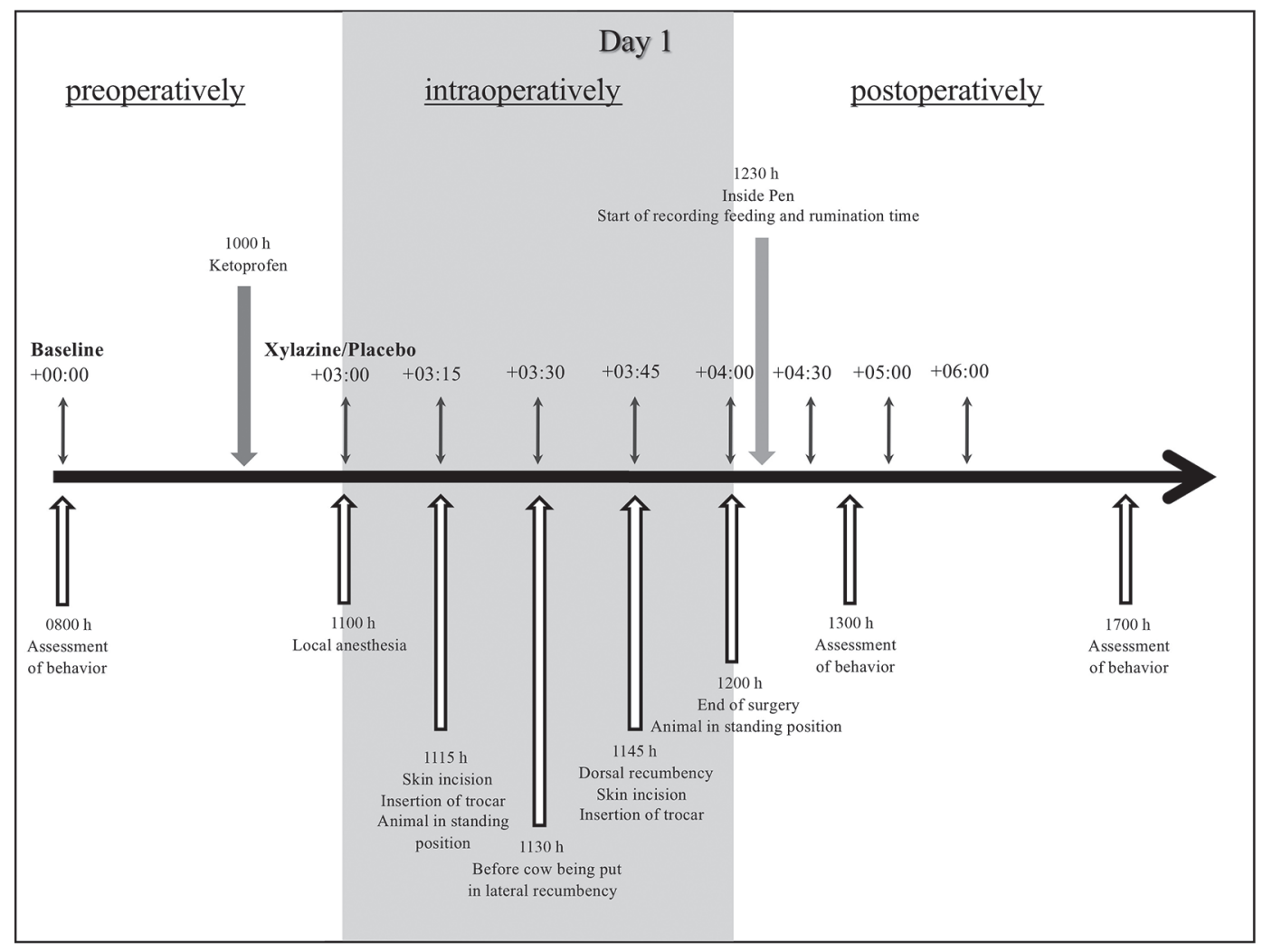

Figure 1. Experimental setup and timings of blood sampling for the determination of effects of xylazine on cortisol and substance P in blood plasma during and after laparoscopic abomasopexy, and on behavior and feeding and rumination time for d 1. Start of surgery was defined as $1100 \mathrm{~h}$, and end of surgery at $1200 \mathrm{~h}$. Animals were then brought back to their pens, and feeding and rumination time was recorded.

\section{Housing and Husbandry}

All cows were examined by a veterinarian at least once daily. For the duration of the study, cows were housed in individual pens. Cows had no visual or physical contact, but could hear other cows. Cows were kept on straw and had free access to water and mineral licks at all times. All cows were fed with feed that was brought by their owners, and hay. Cows were milked twice daily.

\section{Catheterization and Treatment Administration}

On the day of the presentation to the clinic (day before surgery), a 14 gauge $\times 5 \mathrm{~cm}$ catheter (Cavafix; Certo Splittocan 335, B. Braun Melsungen AG, Melsungen, Germany) was placed in a jugular vein after local infiltration of the skin with Procain 2\% (Procasel-2\%, Selectavet, Weyarn-Holzolling, Germany). Initial blood samples were then taken and an admission examination was performed. On the day of admission, all cows were treated with an infusion of $10 \mathrm{~L}$ of $0.9 \%$ saline and at least $1 \mathrm{~L}$ of $40 \%$ glucose. All cows received benzyl penicillin procaine $(20,000 \mathrm{IU} / \mathrm{kg}$ of $\mathrm{BW}$ i.m.;
Procain-Penicillin, WDT, Wertingen, Germany) once every day from the day before the surgery until the last day of the study (d 2) and between 3 and $8 \mathrm{~d}(5$ $\pm 1 \mathrm{~d})$ in total depending on their concurrent diseases. Ketoprofen $(3 \mathrm{mg} / \mathrm{kg}$ of BW i.v.; Rifen $100 \mathrm{mg} / \mathrm{mL}$, Vetoquinol, Ismaning, Germany) was administered to all cows at $1000 \mathrm{~h}$ on the day of the surgery (d 1) and on the day after the surgery (d 2). Groups were either treated with xylazine $(0.02 \mathrm{mg} / \mathrm{kg}$ of BW i.v.; Xylazin $2 \%$, Serumwerk Bernburg, Bernburg, Germany; XYL) or with the equivalent volume of $0.9 \%$ saline $(\mathrm{CON}) 15$ min before skin incision. The person administering the drugs and performing the behavioral assessments did not know which group the animals had been assigned to. Local anesthesia with $10 \mathrm{~mL}$ of procaine hydrochloride (Procamidor $20 \mathrm{mg} / \mathrm{mL}$, WDT) was performed on all incision sites $(\mathrm{n}=4)$.

\section{Laparoscopic Abomasopexy}

The LA was performed by a surgeon from the Clinic for Ruminants with Ambulatory and Herd Health Services. For the LA, the originally described instruments (Janowitz, 1998) and a $180^{\circ}$ hydraulic tilt table (Beh- 
rhorst-Rahden) were used. Each cow was positioned against the tilt table with her right flank at $1045 \mathrm{~h}$. The head was then secured and the animal strapped to the table with a thoracic and abdominal belt. Surgery was performed as described (Janowitz, 1998). The surgery was conducted according to a strictly scheduled standardized protocol. At $1100 \mathrm{~h}$, local anesthesia was administered, which was defined as the start of the surgery. The first skin incision was performed at 1115 h. Skin incision in dorsal recumbency was performed $6.05 \pm 2.09 \mathrm{~min}$ after local anesthesia. Surgery ended at $1200 \mathrm{~h}$. A pneumoperitoneum was created by the use of 40 to $45 \mathrm{~L}$ on average of $\mathrm{CO}_{2}$ in each cow. Cows were brought back to their pen at $1200 \mathrm{~h}$.

\section{Collection of Blood Samples}

The schedule of blood sampling for determination of plasma SP concentrations (PSPC) and plasma cortisol concentrations (PCC) is given in Figure 1. Blood was taken at the day of surgery 180 min before the start of the surgery for baseline cortisol and SP concentration (0800 h, +00:00). Start of the surgery was defined as the moment of application of local anesthesia to the left flank (1100 h, +03:00). Further blood samples were taken $15,30,45,60,90,120$, and $180 \mathrm{~min}$ and $24 \mathrm{~h}$ after the start of the surgery $(+03: 15,+03: 30,+03: 45$, $+04: 00,+04: 30,+05: 00,+06: 00,+00: 27)$. Before each blood sampling, the i.v. catheter was flushed with $0.9 \%$ saline and $2 \mathrm{~mL}$ of blood was discarded. Blood samples were then taken with a new syringe and the catheter was flushed again. Blood samples were transferred to 2-mL EDTA tubes right after sampling. The EDTA tubes for SP samples were spiked with $9 \mu \mathrm{L}$ of aprotinin per tube and were kept in a refrigerator or on ice at all times. Blood samples for both SP and cortisol were kept on ice and brought to the laboratory of the Clinic for Ruminants with Ambulatory and Herd Health Services. All samples were centrifuged within $2 \mathrm{~h}$ after blood collection $\left(4^{\circ} \mathrm{C}, 1,600 \times g\right.$ for $\left.15 \mathrm{~min}\right)$. Blood plasma was kept at $-20^{\circ} \mathrm{C}$ until analysis.

\section{Cortisol and Substance P Analysis}

Laboratory technicians who did the analysis of PSPC and PCC did not know the group assignment of the animal. Determination of PCC was done with a Cortisol ELISA Kit (DRG Instruments GmbH, Germany). Optical densities were determined in duplicate, and means were used for the calculation of concentrations. Lower and upper limits of quantification for the cortisol ELISA Kit were 1.3 and $800 \mathrm{ng} / \mathrm{mL}$. The intra- and interassay coefficient of variation was calculated to be $16 \%$. Determination of PSPC was done with a Sub- stance P ELISA kit (Enzo, Enzo Life Sciences GmbH, Lörrach, Germany). Optical densities were determined in duplicate, and means were used for the calculation of concentrations. Lower and upper limits of quantification for the Substance P ELISA kit were 64,047 and $10,000 \mathrm{pg} / \mathrm{mL}$. The intra- and interassay coefficient of variation was calculated to be $28 \%$.

\section{Feeding and Rumination Times}

Feeding and rumination times were recorded using a specially designed halter (RumiWatch system, Itin and Hoch GmbH, Bennwil, Switzerland), which has been evaluated and described in recent literature (Rombach et al., 2018, 2019). All animals were fitted with the halter directly after the surgery at $1200 \mathrm{~h}$, and feeding and rumination times were recorded for $24 \mathrm{~h}$. Data are given for 11 animals in CON and 12 animals in XYL because the halter was not working on 5 animals. All feedstuffs were weighed before each feeding and the leftovers again afterward as long as the feeding and rumination time was recorded for each animal except for one animal in CON.

\section{Behavioral Scoring}

Behavioral scoring was always done by 1 of 2 trained people. Behavioral scoring on the day of surgery and the following day $(0800,1300$, and $1700 \mathrm{~h}$ on both days) were assessed by assigning scores for heart rate, respiratory rate, activity, position of the head, expression of eyes, muzzle, and ears, and vocalization. Individual aspects of were recorded as either yes or no (behavioral protocol is shown in Supplemental Table S1; https://doi.org/10.3168/jds.2020-18523). During surgery, behavior was scored by assigning scores for the different steps of the LA. Scores were awarded for head movements, movements of ears, vocalization, and evasive movements (moving forward, backward, or to the side; trying to get away from the surgeon; or kicking in the standing animal) as yes or no. Behavior was observed during administration of local anesthesia, insertion of the trocar, creation of a pneumoperitoneum, and suturing of the skin in the standing animal, while bringing the animal in left lateral recumbency and during fixation of the legs, while bringing the animal in dorsal recumbency, and during administration of local anesthesia, insertion of trocar, capturing toggle and suturing of skin in dorsal recumbency, fixation of toggle, and loosening of the legs in lateral recumbency and bringing the animal back into a standing position and into the stable (behavioral protocol during surgery is given in Supplemental Table S2; https://doi.org/10 $.3168 /$ jds.2020-18523). 
Table 1. Clinical findings and blood values at admission exam in animals of the control group (CON, $\mathrm{n}=14)$ and xylazine-treated group (XYL, $\mathrm{n}=14)$

Findings at admission exam

\begin{tabular}{|c|c|c|}
\hline \multirow[b]{2}{*}{ Parameter (reference range) } & \multicolumn{2}{|l|}{ 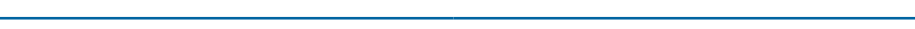 } \\
\hline & $\mathrm{CON}$ & XYL \\
\hline Heart rate (beats per min) & $82.4 \pm 15.4(60-108)$ & $82.3 \pm 8.5(68-92)$ \\
\hline Total protein $(\mathrm{g} / \mathrm{L} ; 60-80 \mathrm{~g} / \mathrm{L})$ & $76.6 \pm 7.8(66.2-90.8)$ & $77.5 \pm 7.2(61.5-88.5)$ \\
\hline $\mathrm{BHB}(\mathrm{mmol} / \mathrm{L} ;<1 \mathrm{mmol} / \mathrm{L})$ & $2.38 \pm 1.42(0.7-5.85)$ & $1.86 \pm 1.32(0.24-4.86)$ \\
\hline Ionized $\mathrm{Ca}(\mathrm{mmol} / \mathrm{L} ; 1-1.3 \mathrm{mmol} / \mathrm{L})$ & $1.08 \pm 0.10(0.98-1.31)$ & $1.09 \pm 0.09(0.98-1.24)$ \\
\hline Glutamate dehydrogenase $(\mathrm{U} / \overline{\mathrm{L}} ; \leq 16 \mathrm{U} / \mathrm{L})$ & $48.93 \pm 55.13(7.16-220.89)$ & $104.93 \pm 182.93(8.59-716.85)$ \\
\hline Rumen chloride $(\mathrm{mmol} / \mathrm{L} ; \leq 30 \mathrm{mmol} / \mathrm{L})$ & $46.8 \pm 15.5(20-68)^{2}$ & $46.8 \pm 15.4(20-69)^{2}$ \\
\hline Days postpartum & $12.8 \pm 8.0(3-36)^{3}$ & $31.6 \pm 61.6(5-243)$ \\
\hline Diagnosed with endometritis ( $\mathrm{n}$ out of 14 ) & 5 & 8 \\
\hline Diagnosed with subclinical mastitis (n out of 14 ) & 2 & 1 \\
\hline Diagnosed with digital dermatitis (n out of 14) & 3 & 2 \\
\hline Diagnosed with laminitis (n out of 14) & 1 & 0 \\
\hline
\end{tabular}

${ }^{1}$ Values are given as mean with SD and range in parentheses.

${ }^{2} \mathrm{n}=12$.

${ }^{3} \mathrm{n}=1$.

\section{Statistical Analysis}

Data analysis was performed using R 3.6.3 (2020-0229, R Foundation for Statistical Computing, Vienna, Austria). Results with a $P$-value $<0.05$ were considered statistically significant. A multiple linear mixed effects model was used to study cortisol, SP, food intake, and blood parameter (glucose, partial pressure $(\mathbf{p})$ of $\mathrm{O}_{2}$, and $\mathrm{pCO}_{2}$ ) values. A baseline concentration of a parameter of interest +00:00 (as a covariate), time, and group were used as fixed effects with a random effect of animal. Normality and homoscedasticity of residuals were assessed via visual residual-diagnostics. Due to the nonnormally distributed and heteroskedastic residuals, data for the final model were log-transformed. The homogeneity of variances across groups was assessed via Levene's test. Autoregressive heterogeneous correlation structure was then applied to improve the mixed effects model, where comparison of models (without any or with different correlation structures) was based on Akaike's information criterion and pseudo- $\mathrm{R}^{2}$. Due to the exploratory approach of the study, correction of the $P$-value for multiple comparisons was not performed. A Spearman's correlation test was used to assess the correlation between PCC and PSPC. The differences in feeding and rumination patterns between unpaired CON and XYL groups were assessed via the unpaired 2 sample $t$-test in case of normally distributed data and via Wilcoxon rank sum test in case of not normally distributed data. Difference in behavior between groups during and after the surgery was studied via a logistic mixed effects model, with time points as fixed and animal as a random effect.

\section{RESULTS}

\section{Clinical Examination, Blood Values, and Outcome}

Results of clinical examination of animals in CON and XYL are given in Table 1. In CON, one cow was euthanized $3 \mathrm{~d}$ postoperatively due to a perforated abomasal ulcer and peritonitis. In XYL, all cows were discharged to go home.

\section{Laparoscopic Abomasopexy}

In CON, duration between administration of $0.9 \%$ $\mathrm{NaCl}$ (placebo) and first skin incision was $15 \mathrm{~min}$ in all cows. Duration of surgery (from first skin incision to animal standing again after procedure) was between 37 and $46 \mathrm{~min}(40.6 \pm 3.1 \mathrm{~min})$. In XYL, duration between administration of xylazine and first skin incision was $15 \mathrm{~min}$ in 13 cows and $20 \mathrm{~min}$ in 1 cow. Duration of surgery ranged from 35 to $48 \mathrm{~min}(40.6 \pm 3.3 \mathrm{~min})$. The surgery could be performed in all animals without adverse effect due to influence of xylazine, and no animal went down or tried to go down before being put into lateral recumbency. 


\section{Cortisol}

The PCC of both CON and XYL over the course of the study are given in Figure 2. Mean baseline PCC was $22 \pm 10.77 \mathrm{ng} / \mathrm{mL}$ in CON and $16.01 \pm 5.96 \mathrm{ng} /$ $\mathrm{mL}$ in XYL. No statistically significant difference was observed between baseline PCC between groups. In $\mathrm{CON}$, mean PCC were $23.83 \pm 16.90 \mathrm{ng} / \mathrm{mL}$ at $1100 \mathrm{~h}$ (after administration of $\mathrm{NaCl}$ ), and increased after the start of the surgery. Highest mean PCC were reached at +04:00 (cow in standing position again) with $50.24 \pm$ $24.32 \mathrm{ng} / \mathrm{mL}$. In XYL, mean PCC were $17.82 \pm 7.86 \mathrm{ng} /$ $\mathrm{mL}$ directly after administration of xylazine $(+03: 00)$. After the administration of xylazine, mean PCC concentrations decreased until the moment when animals were put in dorsal recumbency $(+03: 45)$, whereupon mean PCC increased again. Mean PCC were lower at all times in XYL compared with CON. Mean PCC concentrations was significantly lower in XYL compared with $\mathrm{CON}$ at $+03: 30(P=0.03)$. In comparison with $+03: 00$, mean $\mathrm{PCC}$ in CON were significantly higher at $+03: 45(P<0.01),+04: 00(P<0.01)$, and $+04: 30(P$ $<0.01)$ and significantly lower at $+27: 00(P<0.01)$. In XYL, mean PCC were significantly lower at $+03: 15(P$ $=0.02),+03: 30(P<0.01)$, and $+27: 00(P<0.01)$ and significantly higher at $+04: 00(P<0.01)$ and $+4: 30(P$ $<0.01)$ compared with $+03: 00$.

\section{Substance $P$}

Mean baseline PSPC was $555.37 \pm 252.77 \mathrm{pg} / \mathrm{mL}$ in CON and $490.60 \pm 219.62 \mathrm{pg} / \mathrm{mL}$ in XYL. No statistically significant difference was observed between baseline PSPC or PSPC at +03:00 between groups. No significant differences were observed between groups at any time, nor within groups at any of the times of blood sampling following the start of the surgery (Figure 3).

\section{Correlation Between Cortisol and Substance P}

In $\mathrm{CON}$ as well as in XYL, no correlation was observed between PCC and PSPC at any time. In CON, there was trend to significance at $+06: 00(\mathrm{rho}=0.53$, $P<0.1)$.

\section{Glucose Levels in the Blood}

Mean blood glucose levels were $5.9 \pm 2.3 \mathrm{mmol} / \mathrm{L}$ in CON and $5.31 \pm 2.07 \mathrm{mmol} / \mathrm{L}$ in XYL at admission and $4.6 \pm 1.5$ in $\mathrm{CON}$ and $4.26 \pm 1.26$ in XYL

Group $\phi$ CON $\uparrow$ XYL

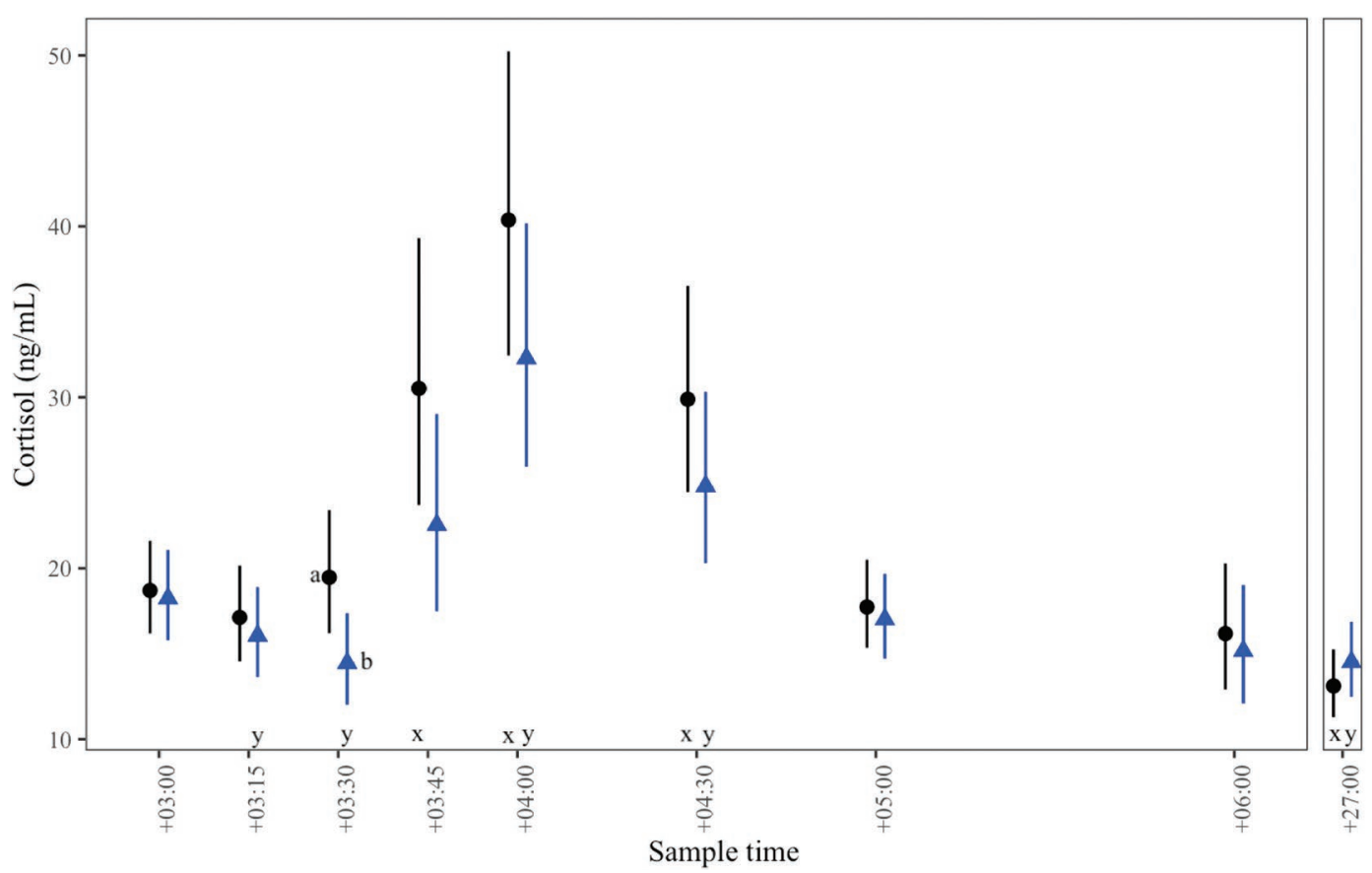

Figure 2. Course of plasma cortisol concentration in cows in CON ( $\mathrm{n}=14$, without administration of xylazine before surgery, in black) and XYL ( $\mathrm{n}=14$, with administration of xylazine before surgery, in blue). Mean values are given as $\bullet$ for CON and $\boldsymbol{\Delta}$ for XYL with 95\% CI. Start of surgery was at $1100 \mathrm{~h}(+03: 00)$. Letters denote the differences $(P<0.05)$ between treatments $(\mathrm{a}, \mathrm{b})$ or from time $+03: 00(\mathrm{x}$ for CON, y for XYL). 
at $\mathrm{T}+$ 00:00 (baseline). Glucose levels were significantly lower in CON than in XYL at $+03: 45(P=0.03)$ and $+04: 30(P=0.03)$. In CON, mean blood glucose levels were significantly higher at $+03: 00$ compared with $+27: 00(P<0.01)$. In XYL, blood glucose levels were significantly higher at $+03: 45(P<0.01),+04: 00(P=$ $0.01)$, and $+04: 30(P=0.02)$ compared with $+03: 00$, and significantly lower at $+27: 00(<0.01)$. Mean blood glucose levels are given in Figure 4.

\section{$\mathrm{pO}_{2}$ Levels in the Blood}

Mean $\mathrm{pO}_{2}$ was $43.0 \pm 4.3 \mathrm{mmHg}$ in $\mathrm{CON}$ and $40.7 \pm$ $6.9 \mathrm{mmHg}$ in XYL at + 00:00 (baseline). No significant differences were observed between groups at any time (Figure 5). In $\mathrm{CON}$, mean $\mathrm{pO}_{2}$ was significantly lower at $+03: 45(P<0.01)$ and at $+04: 00(P<0.01)$ than at $+03: 00$. In XYL, $\mathrm{pO}_{2}$ was significantly lower at $+03: 45$ $(P<0.01)$ and at $+04: 30(P=0.04)$ compared with $+03: 00$.

\section{$\mathrm{pCO}_{2}$ Levels in the Blood}

Mean $\mathrm{pCO}_{2}$ was $44.0 \pm 3.7 \mathrm{mmHg}$ in $\mathrm{CON}$ and 44.1 $\pm 4.8 \mathrm{mmHg}$ in XYL at $+00: 00$ (baseline). Mean $\mathrm{pCO}_{2}$ was significantly higher in XYL compared with CON at $+03: 30(P=0.05$; Figure 6$)$. No significant differences were observed within CON. In XYL, $\mathrm{pCO}_{2}$ was significantly higher at $+03: 15(P<0.01),+03: 30(P$ $<0.01),+03: 45(P<0.01)$, and $+04: 30(P=0.01)$ compared with $+03: 00$.

\section{Behavioral Scoring}

Mixed effects models for each behavioral pattern during surgery (head movements, movement of ears, vocalization, and evasive movements) and after surgery (heart rate, breathing rate, activity, position of head, eyes, nose, ears, and vocalization) did not show any significant differences in behavior at the different time points during the surgery and on $d 1$ and 2 .

\section{Feeding and Rumination Times}

Feeding and rumination times are given in Figure 7. Feeding time for the $24 \mathrm{~h}$ after surgery was 262.6 $\pm 136.3 \mathrm{~min}$ in CON and $267.9 \pm 151.2 \mathrm{~min}$ in XYL. Animals in CON ate on $4.5 \pm 3.3 \mathrm{~kg}$ in the afternoon after the surgery and $4.1 \pm 2.4 \mathrm{~kg}$ in the first morning postoperatively (total of $8.2 \pm 5.4 \mathrm{~kg}$ ). Animals in XYL

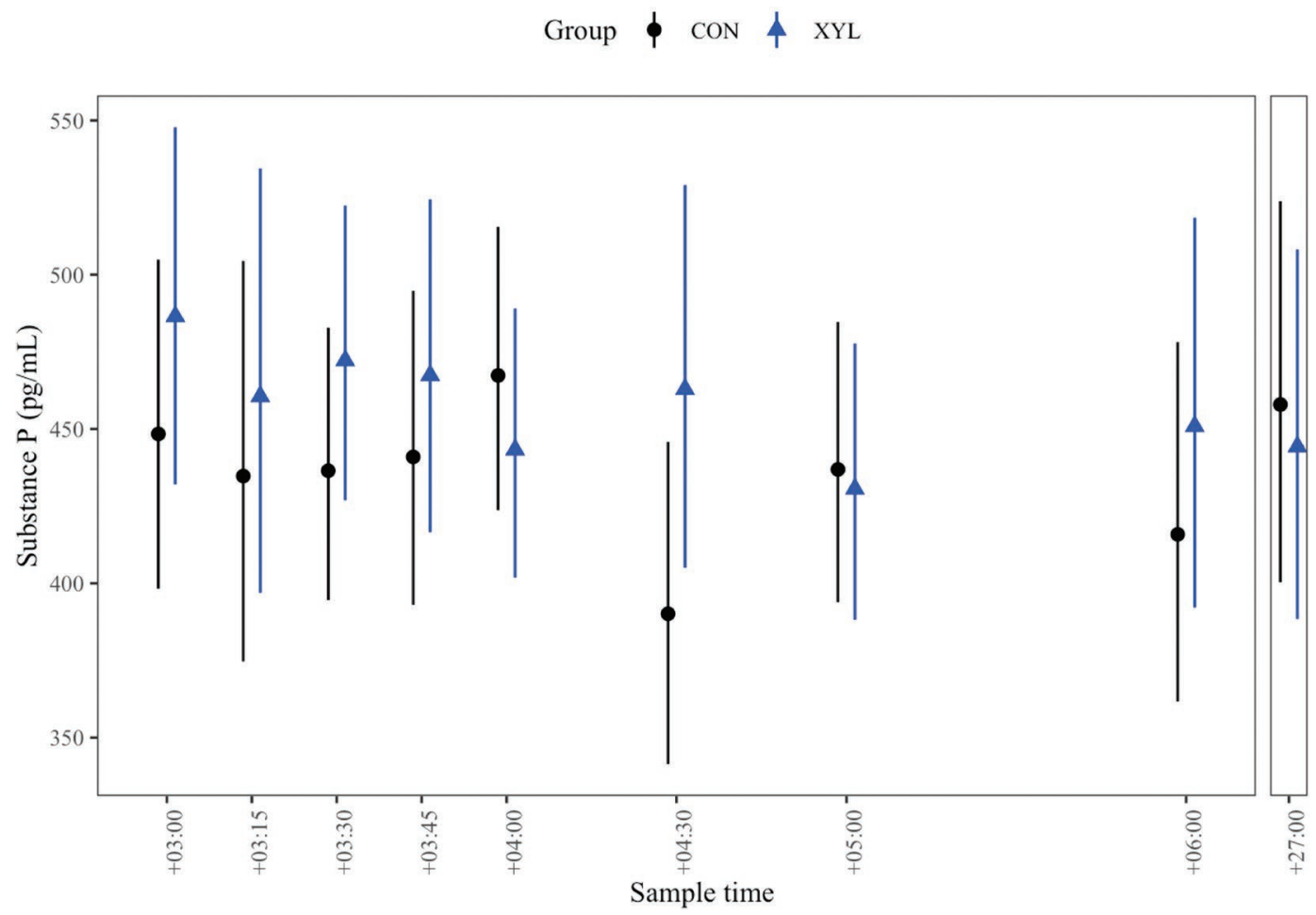

Figure 3. Course of plasma substance $\mathrm{P}$ concentration in cows in CON ( $\mathrm{n}=14$, without administration of xylazine before surgery, in black) and XYL ( $\mathrm{n}=14$, with administration of xylazine before surgery, in blue). Mean values are given as $\boldsymbol{\bullet}$ for CON and $\boldsymbol{\Delta}$ for XYL with $95 \%$ CI. Start of surgery was at $1100 \mathrm{~h}$ (+03:00). No significant differences were observed between substance P concentrations of cows of CON and XYL at any time. 
ate $4.4 \pm 3.9 \mathrm{~kg}$ in the afternoon after the surgery and $4.8 \pm 3.2 \mathrm{~kg}$ in the first morning postoperatively (total of $9.2 \pm 6.0 \mathrm{~kg}$ ). No significant difference was observed between groups in time or in mass of feedstuff spent feeding. Time spent ruminating was $280.8 \pm 199.4 \mathrm{~min}$ in CON and 245.6 $\pm 131.6 \mathrm{~min}$ in XYL. No significant difference was observed between groups. Number of boli per rumination bout was $21.5 \pm 6.4$ in CON (total of $226.3 \pm 214.2$ in $24 \mathrm{~h}$ ) and $20.4 \pm 7.7$ (total of 280.4 \pm 147.2 in $24 \mathrm{~h}$ ) in XYL. No significant difference was observed between groups. Chews per bolus were 46.6 \pm 6.9 in CON and $55.5 \pm 0.4$ in XYL. Animals in XYL showed a significantly higher number of chews per bolus in the first $24 \mathrm{~h}$ after surgery $(P=0.02)$.

\section{DISCUSSION}

This study was conducted to describe the influence of xylazine on PCC and PSPC during and after a laparoscopic fixation of a LDA. The administration of xylazine before LA results in lower PCC concentrations during surgery and a higher number of bouts per bolus while ruminating after surgery. Abdominal surgeries are known to be stressors to cattle (Mudroň et al., 2005). Cortisol is an extensively reviewed indicator for stress, pain, and fear in cattle (Faulkner and Weary, 2000; Coetzee et al., 2008). In the present study, animals that received xylazine before surgery showed significantly lower PCC 15 and 30 min into the surgery compared with the start of the surgery compared with animals that received a placebo. Animals in $\mathrm{CON}$ showed a significant increase of PCC 45 (dorsal recumbency), 60 (end of surgery), and 90 min after the start of the surgery compared with the start of the surgery. Animals in XYL showed significantly higher PCC for a shorter duration of time at 60 and 90 after the start of the surgery. Also, PCC in XYL was lower at all sample times on d 1 compared with $\mathrm{CON}$, and significantly lower at $+03: 30$.

Those results indicate that animals experience less stress during LA after the administration of xylazine, especially before being put into lateral and then dorsal recumbency and staying in dorsal recumbency. Previous research showed that cattle experience less stress when being put into lateral recumbency for claw treatments after administration of xylazine (Rizk et al., 2012b). In our study, animals were not kept in lateral but put into dorsal recumbency, which might have resulted in higher PCC in XYL and significantly higher PCC in CON 15 min after putting the animals into dorsal recumbency.

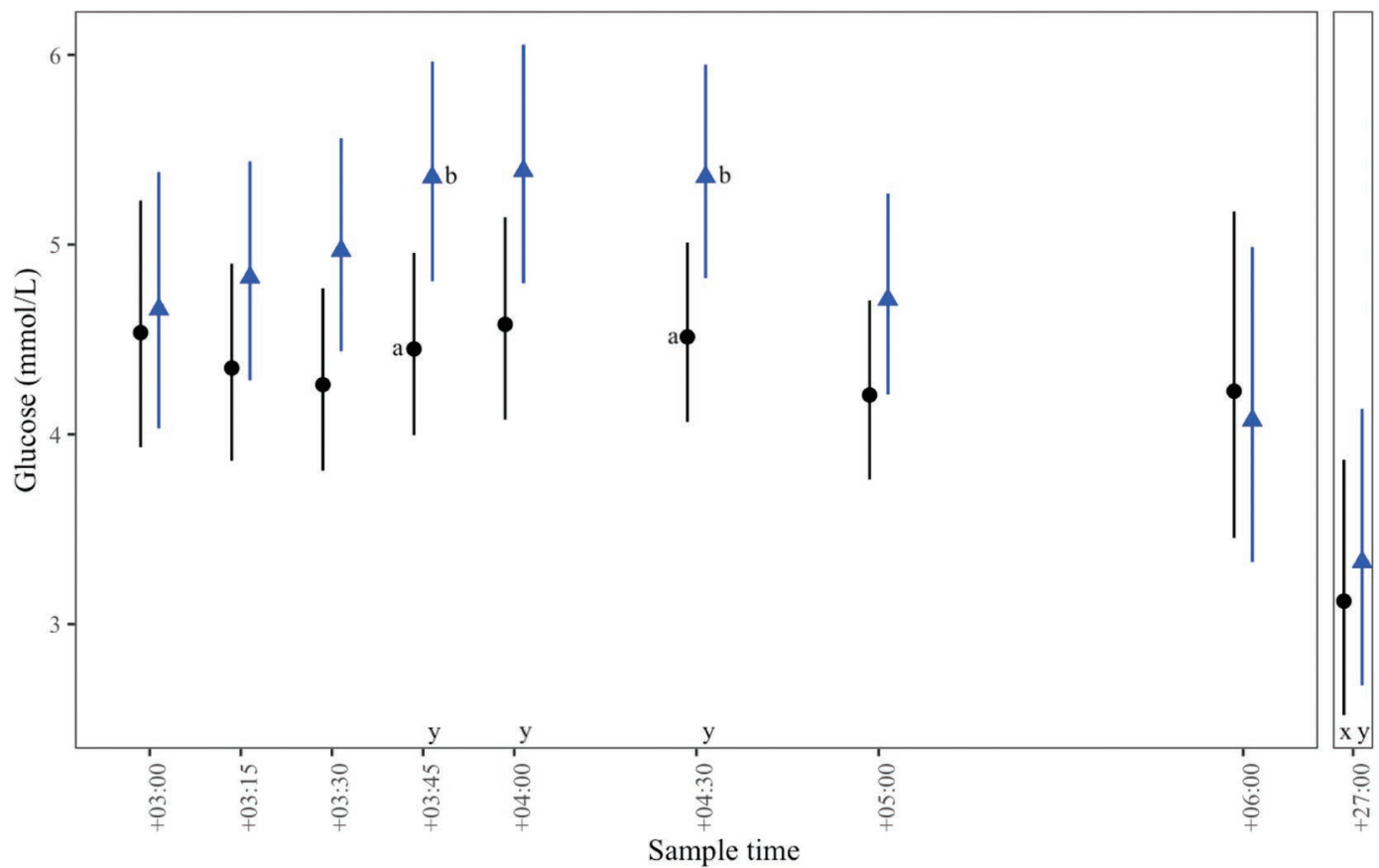

Figure 4. Course of glucose concentrations in cows in CON $(\mathrm{n}=14$, without administration of xylazine before surgery, in black) and XYL $(\mathrm{n}=14$, with administration of xylazine before surgery, in blue). Mean values are given as $\bullet$ for CON and $\boldsymbol{\Delta}$ for XYL with 95\% CI. Start of surgery was at $1100 \mathrm{~h}(+03: 00)$. Letters denote the differences $(P<0.05)$ between treatments $(\mathrm{a}, \mathrm{b})$ or from time $+03: 00(\mathrm{x}$ for $\mathrm{CON}, \mathrm{y}$ for XYL). 
The sedative effect of xylazine starts 3 min after i.v. administration, and the half-time in plasma is 30 to 36 min in cattle (Ebert et al., 2002; Löscher, 2003). In the present study, xylazine or the placebo was administered at $1100 \mathrm{~h}$, skin incision was done at $1115 \mathrm{~h}$, and surgery lasted for $40.6 \pm 3.1 \mathrm{~min}$ in $\mathrm{CON}$ and $40.6 \pm 3.3 \mathrm{~min}$ in XYL. This could explain why animals in XYL showed significantly higher PCC $45 \mathrm{~min}$ after application of xylazine compared with the start of the surgery. However, the PCC increased more slowly compared with animals in CON, which showed significantly higher PCC $15 \mathrm{~min}$ earlier. We used a dose of $0.02 \mathrm{mg}$ of xylazine per kilogram of BW i.v., whereas Rizk and colleagues used a dose of $0.05 \mathrm{mg}$ of xylazine per kilogram of BW i.m. (Rizk et al., 2012a,b). However, considering the route of administration, these 2 doses result in the same effects (Stöber, 1990). The low dose of $0.02 \mathrm{mg}$ of xylazine per kilogram of BW i.v., which animals in XYL were treated with, normally does not result in animals lying down, contrary to higher doses of 0.06 to $0.1 \mathrm{mg}$ per kilogram of BW i.v., which always results in animals lying down (Stöber, 1990). In the present study, administration of a low dose of xylazine did not result in animals lying down during the surgery while standing next to the tilt table. Going down during step 1 of the surgery would interfere with the course of the surgery and the creation of a pneumoperitoneum (Roy and Rousseau, 2017) and is a concern of veterinarians performing a LA.

Substance $\mathrm{P}$ is a neurotransmitter of the family of tachykinins, composed of 11 amino acids (Hökfelt et al., 2001; Hunt and Mantyh, 2001; Hofmann, 2006). In veterinary medicine, $\mathrm{SP}$ is described as a more objective indicator for pain than cortisol (Coetzee et al., 2008; Tschoner et al., 2018), but it is also known that SP is found in areas of the neuroaxis, which are involved in the integration of stress, pain, and anxiety (Coetzee, 2011) and that SP concentrations are elevated in beef steers after transportation (Van Engen et al., 2014). In the present study, PSPC did not increase during the course of the surgery in CON or XYL. This could be due to the fact that SP is primarily released from Cfibers (Snijdelaar et al., 2000), which conduct pain with a much slower speed than $\mathrm{A} \beta$ or $\mathrm{A} \delta$ fibers (Henke and Erhardt, 2001; Muir and Woolf, 2001). However, SP neither rose in the hours after the surgery nor up until $24 \mathrm{~h}$ after the surgery. Comparing these results with those of studies in which SP concentrations increased right after a painful stimulus, such as castration (Coetzee et al., 2008) or umbilical surgery (Tschoner et al., 2018), it is possible that LA is not as painful as other surgeries, especially when animals are treated with a

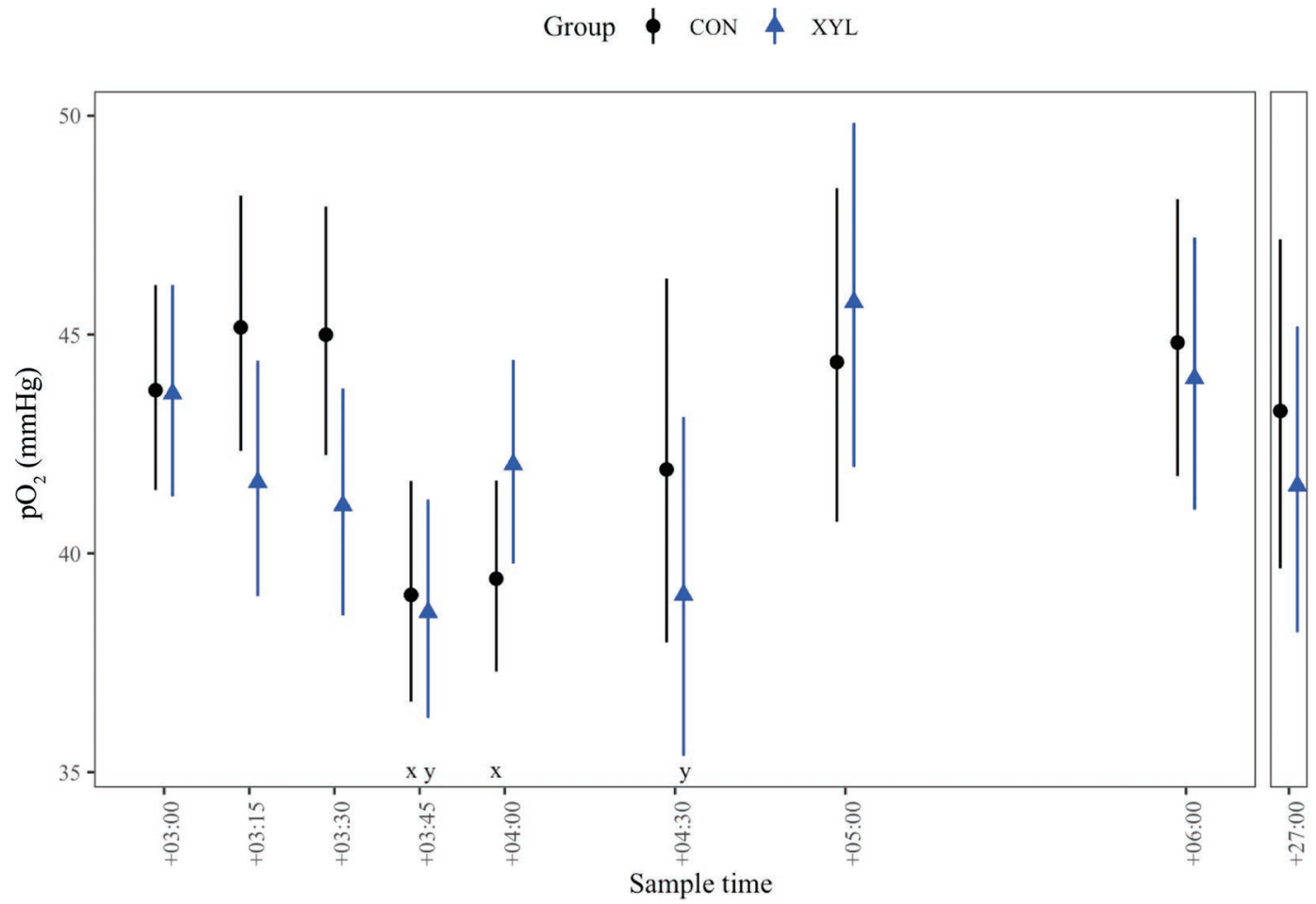

Figure 5. Course of mean partial pressure of $\mathrm{O}_{2}\left(\mathrm{pO}_{2}\right)$ levels in cows in $\mathrm{CON}(\mathrm{n}=14$, without administration of xylazine before surgery, in black) and XYL ( $\mathrm{n}=14$, with administration of xylazine before surgery, in blue). Mean values are given as $\bullet$ for CON and $\boldsymbol{\Delta}$ for XYL with $95 \%$ CI. Start of surgery was at $1100 \mathrm{~h}(+03: 00)$. Letters denote the differences $(P<0.05)$ from time $+03: 00$ (x for CON, y for XYL). 
Group $\phi \operatorname{CON} \uparrow \mathrm{XYL}$

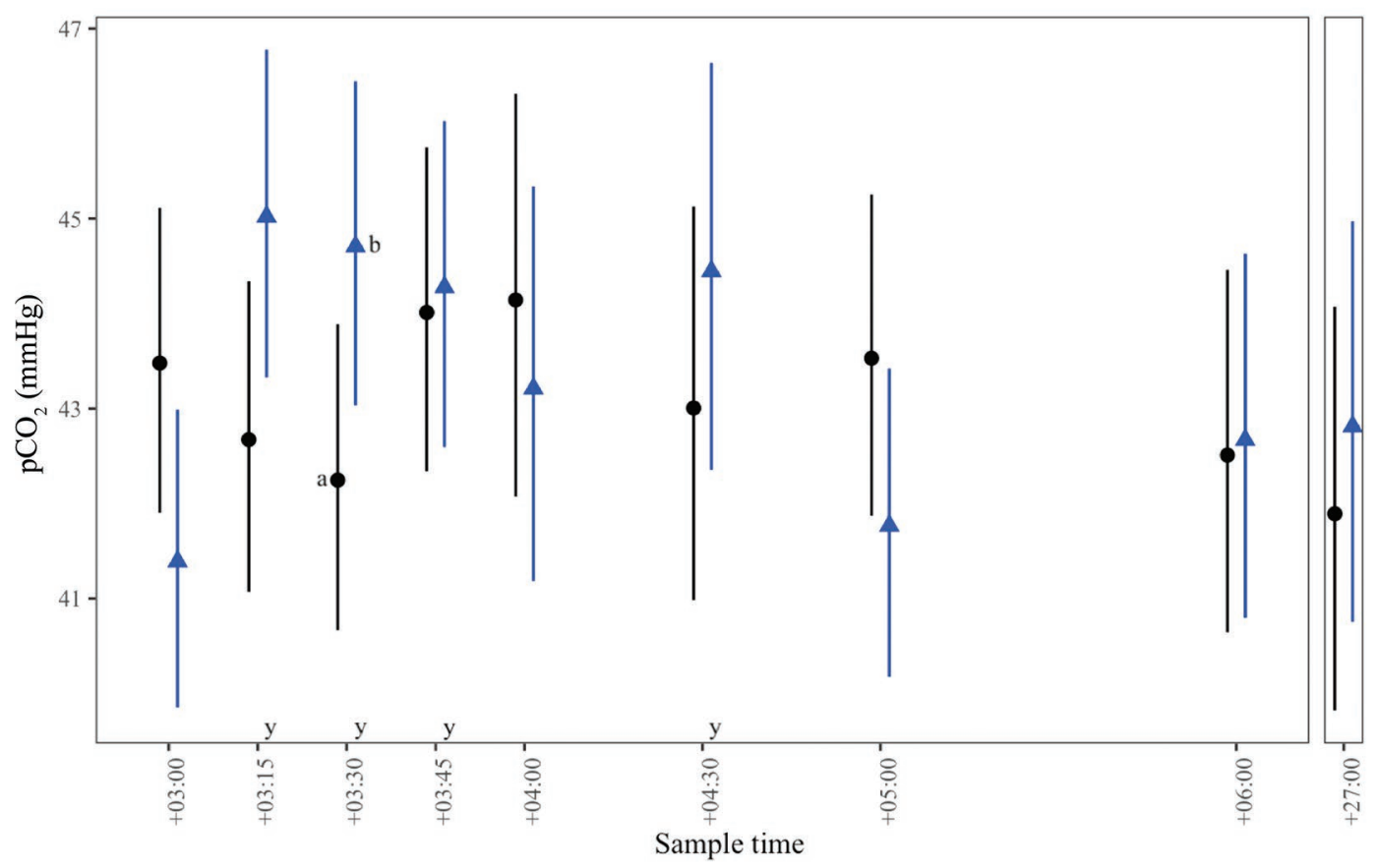

Figure 6. Course of mean partial pressure of $\mathrm{CO}_{2}\left(\mathrm{pCO}_{2}\right)$ levels in cows in $\mathrm{CON}(\mathrm{n}=14$, without administration of xylazine before surgery, in black) and XYL ( $\mathrm{n}=14$, with administration of xylazine before surgery, in blue). Mean values are given as $\boldsymbol{\bullet}$ for CON and $\boldsymbol{\Delta}$ for XYL with $95 \%$ CI. Start of surgery was at $1100 \mathrm{~h}(+03: 00)$. Letters denote the differences $(P<0.05)$ between treatments $(\mathrm{a}, \mathrm{b})$ or from time $+03: 00(\mathrm{x}$ for CON, y for XYL).

nonsteroidal antiinflammatory drug and a local anesthetic in the course of multimodal pain management before surgery, as in the present study. This so-called pre-emptive analgesia prevents the onset of nociception and the perception of nociception by the patient (Otto, 2001; Anderson and Muir, 2005).The combination of a sedative, local anesthesia, and the administration of a nonsteroidal antiinflammatory drug, also known as multimodal pain management (Hudson et al., 2008; Anderson and Edmondson, 2013) could also have prevented a change in PSPC concentrations in the course of the surgery. As we did not have another control group in which animals were submitted to being cast into lateral and then dorsal recumbency without the surgical procedure of a LA, the authors cannot confirm this hypothesis. Animals in both groups received a local anesthetic and ketoprofen, but because only animals in XYL also received xylazine as part of a multimodal pain management and PSPC were stable in both groups, it is also possible that SP truly is an indicator for pain rather than for stress because PSPC did not increase during the stressful LA, as did the PCC. This can also be supported by that fact that there was no correlation between PCC and PSPC concentrations at any time in both groups, which is not in accordance with a recent study in which a positive correlation between cortisol and SP was described (Kasimanickam et al., 2019). If PSPC also increases due to a stressful stimulus, we should have been able to show a positive correlation between both parameters.

By diverting glucose metabolism from the muscle to the brain and other tissues, the flight response is maintained. Stressors, such as an abdominal surgery, are known to increase glucose levels in the blood of hypoas well as normoglycemic cows (Mudroň et al., 2005). This can also be shown in the cows that were sampled for this study. Glucose levels both in CON and in XYL were significantly higher at the start of the surgery than at $1100 \mathrm{~h}$ the following day (d 2), when animals had had the chance to get used to the surroundings and the caretakers, and had not been stressed during the night. Administration of xylazine results in hyperglycemia in sheep (Malhi et al., 2015), as well as in cattle, which is most likely due to stimulation of $\alpha$-2-adrenergic receptors, which suppress the release of insulin (Hsu and Hummel, 1981; Mohammed et al., 2018) or due to stress-induced gluconeogenesis as could be seen in mice (Mohammed et al., 2018). This is in accordance with 


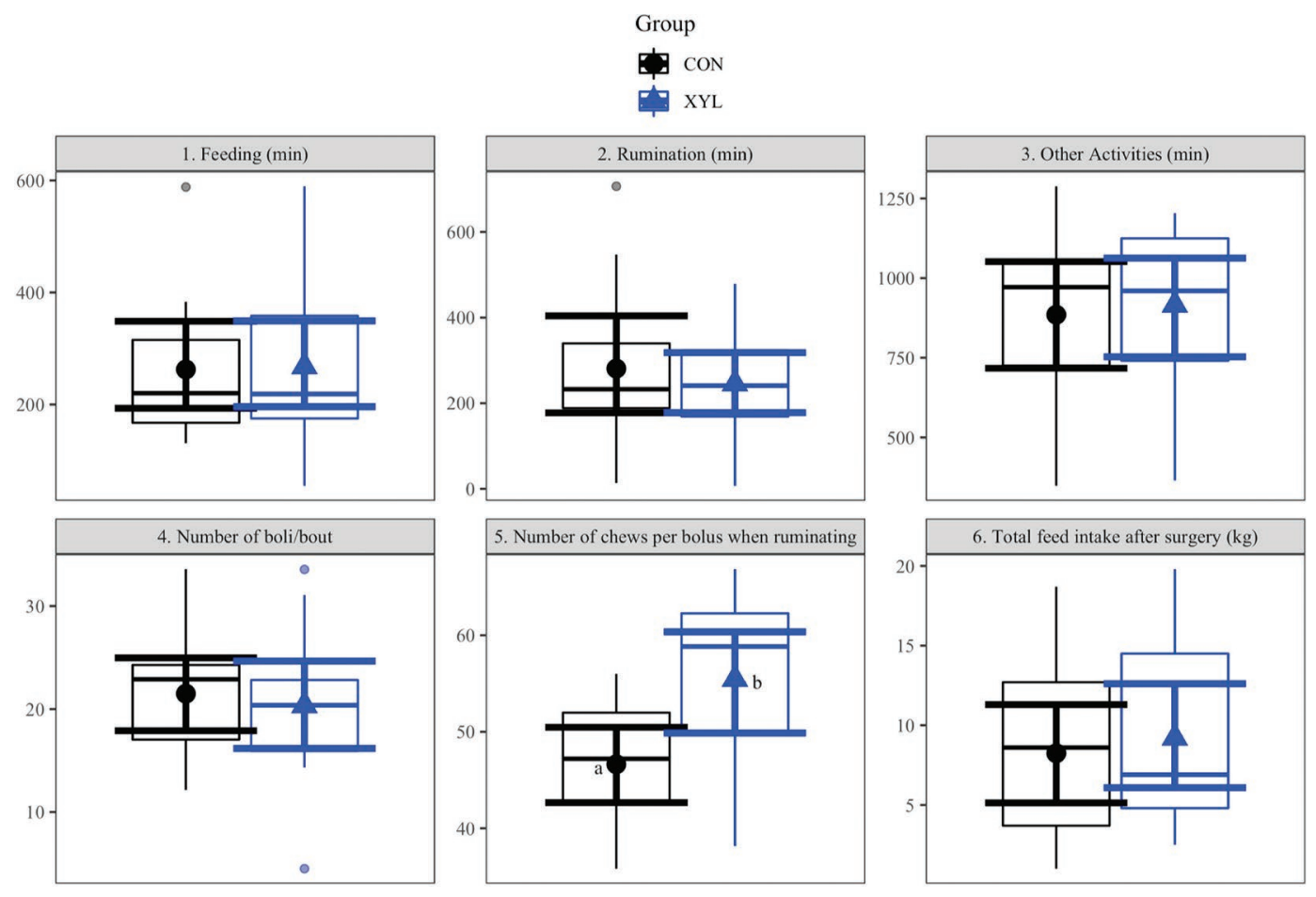

Figure 7. Feeding and rumination in cows in CON $(\mathrm{n}=14$, without administration of xylazine before surgery, in black $)$ and XYL $(\mathrm{n}=14$, with administration of xylazine before surgery, in blue). Mean values are given as $\bullet$ for CON and $\boldsymbol{\Delta}$ for XYL with $95 \%$ CI. Feeding and rumination time were recorded for $24 \mathrm{~h}$ following surgery. Other activities were defined as time not spent feeding or ruminating. Letters denote the differences $(P<0.05)$ between treatments $(\mathrm{a}, \mathrm{b})$. The box represents $50 \%$ of the data. The mid line is the median. The lowest horizontal line (whisker) is the first quartile (Q1) and the highest horizontal line (whisker) is the third quartile (Q3). Dots represent outliners.

our findings. Compared with CON, animals of XYL showed significantly higher blood glucose levels 45,60 , and $90 \mathrm{~min}$ after the start of the surgery, which is in accordance with previous findings (Rizk et al., 2012a).

In the present study, we observed a significant increase of $\mathrm{pCO}_{2}$ in xylazine-treated cows during and 30 min after the surgery, which was also described in other studies (Rizk et al., 2012a). As the pneumoperitoneum was created with $\mathrm{CO}_{2}$ in both groups, the insufflation of $\mathrm{CO}_{2}$ should not be the reason for these findings. Rizk et al. (2012a) showed that lateral recumbency alone results in a decrease of $\mathrm{pO}_{2}$, and that $\mathrm{pO}_{2}$ levels were significantly lower in xylazine-treated animals being put into lateral recumbency, compared with animals that received a placebo. These findings could not be repeated in our study. However, we did not take samples directly after animals were being put into lateral recumbency, but only after they had been put into dorsal recumbency. The $\mathrm{pO}_{2}$ levels decreased both in $\mathrm{CON}$ and XYL after the animals were put into dorsal recumbency, with no significant difference between groups. The administration of xylazine significantly reduces the arterial $\mathrm{pO}_{2}$ in cattle (Hodgson et al., 2002). However, putting calves into dorsal recumbency without prior administration of xylazine also results in a significant decrease of the delivery of $\mathrm{O}_{2}$ via the blood (Meyer et al., 2010). This could explain the fact that in our study, animals in CON and as well as in XYL showed significantly lower $\mathrm{pO}_{2}$ concentrations in the blood after being put into dorsal recumbency than at the start of the surgery.

Contrary to previous studies (Rizk et al., 2012a), we observed no difference in behavior during the surgery or afterward. In all animals, local anesthesia was performed before skin incision and insertion of the trocar, but xylazine results in a potentiation of the analgesic effects of the local anesthetic (Rizk et al., 2012b), which should have resulted in animals in XYL showing less evasive behavior than animals in CON. According to Feist et al. (2008), cattle showed significantly less abnormal position of the ears on the first postoperative day if treated with ketoprofen before claw surgery, compared with control animals. In our study, animals in CON and XYL did not show differences between the expression of eyes or nose or position of the ears, all of which have been described as signs for pain in cattle (Gleerup et al., 2015). Animals in both groups received ketoprofen. Is has been shown that the treat- 
ment with ketoprofen results in almost no head shaking or ear flicking in calves after dehorning (Faulkner and Weary, 2000). The elimination half-life of ketoprofen in plasma of cattle is 0.49 (0.40 to 0.67) h (De Graves et al., 1996). Thus, the treatment of animals at $1000 \mathrm{~h}$ with ketoprofen might have resulted in no significant differences between XYL and CON during the course of the surgery and thereafter. Xylazine, as an $\alpha-2-$ agonist, inhibits the release of norepinephrine and SP (Anderson and Muir, 2005) and thus has an analgesic effect, but the half-time of xylazine is about 30 to 36 min (Ebert et al., 2002; Löscher, 2003) and the majority of metabolites of xylazine in the blood plasma are eliminated after 2 to $4 \mathrm{~h}$ in cattle (Ebert et al., 2002). The decreasing effect of xylazine, along with the effects of ketoprofen in both groups, could also have explained the lack of difference in behavior between groups in the course of surgery and thereafter.

Healthy cows show a daily feeding time of $316 \pm 48$ min and a rumination time of $368 \pm 54$ min with 38 to 60 chews per bolus (Braun et al., 2015b). In the present study, the feeding, as well as the rumination time in CON as well as in XYL, was clearly below these values. However, in a study of differences between feeding and rumination time between cattle of different breeds, feeding time recorded for all animals $(\mathrm{n}=300)$ was $265 \mathrm{~min}$ (Braun et al., 2015c), which is in accordance with our findings. However, cattle with LDA are often diagnosed with concurrent diseases such as mastitis, metritis, endometritis, metabolic diseases, or lameness, which also negatively influence the feeding time (González et al., 2008; Siivonen et al., 2011; Jawor et al., 2012). In our study, 13 out of 28 animals were diagnosed with endometritis, 3 with subclinical mastitis, 5 with digital dermatitis, and 1 with laminitis, which could have resulted in the low feeding times in the animals in our study. Because no significant differences were observed between the mass of feed consumed by cattle, either on the individual days or in total, the fact that sick animals spend longer time feeding on a lesser mass of feed, as has been shown previously (Siivonen et al., 2011), could not be reproduced. Also, animals were kept in individual pens for the duration of the study for the assessment of daily feed intake, which could also have reduced feeding times. Because we did not record the feeding time for longer than $24 \mathrm{~h}$, we cannot make any statement about whether the feeding time increased in the days after the surgery. Feeding time is significantly lower in Brown Swiss than in Holstein Friesian and Swiss Fleckvieh (Braun et al., 2015c). Even though we assessed feeding time for animals of different breeds, we only included one Brown Swiss into our study, so breeds should not have influenced our results. Rumination time is a reliable indicator for the well-being of cattle (Braun et al., 2017). According to previous research, duration of rumination is $441 \mathrm{~min}$ per $24 \mathrm{~h}$ in healthy animals of different breeds with 55 chews per bolus (Braun et al., 2015c). In our study, rumination time was about 160 to 200 min shorter in CON and XYL, respectively. It is known that rumination time decreases in sick animals (Siivonen et al., 2011; Fogsgaard et al., 2012; Braun et al., 2017), and that cattle with higher cortisol levels spent significantly less time ruminating than cattle with lower cortisol levels (Bristow and Holmes, 2007). This could not be confirmed in our study. Animals in XYL showed significantly more chews per bolus than animals in CON, which was still comparable with, or slightly lower than in healthy animals in other studies (Braun et al., 2015b,c). Chews per bolus were clearly higher in XYL $(55.5 \pm 0.4)$ than in cattle in the first 24 $\mathrm{h}$ after a right flank omentopexy for the correction of LDA (43 \pm 6 ), whereas chews per bolus in CON (46.6 \pm 6.9 ) were in accordance with the number of chews per bolus in cattle after right flank omentopexy (Braun et al., 2015a). In our opinion, this is another indicator for the fact, that animals treated with xylazine before LA experience less stress during and after the surgery than animals not treated with xylazine.

Withdrawal times are an important factor for farmers. In our study, all animals were treated with an antibiotic to ensure the same conditions in all animals. The withdrawal times for the xylazine product we used are $1 \mathrm{~d}$ for meat and none for milk in Germany. To the knowledge of the author, other xylazine products have no withdrawal times at all. In Canada, withdrawal times for meat and milk are 2 and 3 d, respectively. In the United States, xylazine use in cattle is extralabel. The use of xylazine for an LA should have no to only a minor negative effect on the increase of milk and meat withdrawal times, depending on the regulations of the country.

\section{CONCLUSIONS}

The present study shows that administration of xylazine before 2-step LA using a tilt table as described by Janowitz in cattle results in reduced PCC during the course of the surgery, and a higher number of chews per bolus while ruminating in the first $24 \mathrm{~h}$ after surgery without the adverse effect of animals lying down during surgery. In our opinion, the administration of a low dose of xylazine $(0.02 \mathrm{mg} / \mathrm{kg}$ i.v. $)$ should be recommended before LA in combination with the administration of an nonsteroidal antiinflammatory drug and a local anesthetic to improve the welfare of cattle during and after the surgical procedure. 


\section{ACKNOWLEDGMENTS}

We thank the team of the Clinic for Ruminants with Herd Health and Ambulatory Services for their help with completing this study. The authors have not stated any conflicts of interest.

\section{REFERENCES}

Anderson, D. E., and M. A. Edmondson. 2013. Prevention and management of surgical pain in cattle. Vet. Clin. North Am. Food Anim. Pract. 29:157-184. https://doi.org/10.1016/j.cvfa.2012.11 .006 .

Anderson, D. E., and W. W. Muir. 2005. Pain management in cattle. Vet. Clin. North Am. Food Anim. Pract. 21:623-635. https://doi .org/10.1016/j.cvfa.2005.07.002.

Braun, U., L. Trösch, and K. Nuss. 2015a. Evaluation of eating and rumination behaviour using a noseband pressure sensor in cows after right-flank laparotomy for correction of left displaced abomasum. Schweiz. Arch. Tierheilkd. 157:345-347. https://doi.org/10 $.17236 /$ sat00025.

Braun, U., T. Tschoner, M. Hässig, and K. Nuss. 2017. Eating and rumination behaviour in cows with traumatic reticuloperitonitis. Schweiz. Arch. Tierheilkd. 159:101-108. https://doi.org/10.17236/ sat00104.

Braun, U., S. Zürcher, and M. Hässig. 2015b. Eating and rumination activity in 10 cows over 10 days. Res. Vet. Sci. 101:196-198. https: //doi.org/10.1016/j.rvsc.2015.05.001.

Braun, U., S. Zürcher, and M. Hässig. 2015c. Evaluation of eating and rumination behaviour in 300 cows of three different breeds using a noseband pressure sensor. BMC Vet. Res. 11:231-236. https://doi .org/10.1186/s12917-015-0549-8.

Bristow, D. J., and D. S. Holmes. 2007. Cortisol levels and anxietyrelated behaviors in cattle. Physiol. Behav. 90:626-628. https://doi .org/10.1016/j.physbeh.2006.11.015.

Coetzee, J. F. 2011. A review of pain assessment techniques and pharmacological approaches to pain relief after bovine castration: Practical implications for cattle production within the United States. Appl. Anim. Behav. Sci. 135:192-213. https://doi.org/10.1016/j .applanim.2011.10.016.

Coetzee, J. F., B. V. Lubbers, S. E. Toerber, R. Gehring, D. U. Thomson, B. J. White, and M. D. Apley. 2008. Plasma concentrations of substance $\mathrm{P}$ and cortisol in beef calves after castration or simulated castration. Am. J. Vet. Res. 69:751-762. https://doi.org/10 .2460 /ajvr.69.6.751.

De Graves, F. J., M. G. Riddell, and J. Schumacher. 1996. Ketoprofen concentrations in plasma and milk after intravenous administration in dairy cattle. Am. J. Vet. Res. 57:1031-1033.

Dirksen, G. 2006. Krankheiten der Verdauungsorgane und der Bauchwand. Pages 357-695 in Innere Medizin und Chirurgie des Rindes. 5th ed. G. Dirksen, H.-D- Gründer, and M. Stöber, ed. Paul Parey Verlag, Stuttgart, Germany.

Ebert, U., H.-H. Frey, and R. Schulz. 2002. Pharmakologie des zentralen Nervensystems (ZNS). Pages 87-138 in Lehrbuch der Pharmakologie und Toxikologie für die Veterinärmedizin. 2nd. H.H. Frey and W. Löscher, ed. Enke, Stuttgart, Germany.

Faulkner, P. M., and D. M. Weary. 2000. Reducing pain after dehorning in dairy calves. J. Dairy Sci. 83:2037-2041. https://doi.org/10 .3168/jds.S0022-0302(00)75084-3.

Feist, M., R. Köstlin, and K. Nuss. 2008. Claw surgery in cattle: The benefit of perioperative analgesics. Tierarztl. Prax. 36:367-376. https://doi.org/10.1055/s-0038-1623861.

Fiore, F., D. Musina, R. Cocco, A. Di Cerbo, and N. Spissu. 2018. Association between left-displaced abomasum corrected with 2-step laparoscopic abomasopexy and milk production in a commercial dairy farm in Italy. Ir. Vet. J. 71:20. https://doi.org/10.1186/ s13620-018-0132-2.

Fogsgaard, K. K., C. M. Røntved, P. Sørensen, and M. S. Herskin. 2012. Sickness behavior in dairy cows during Escherichia coli mas- titis. J. Dairy Sci. 95:630-638. https://doi.org/10.3168/jds.2011 -4350 .

Gleerup, K. B., P. H. Andersen, L. Munksgaard, and B. Forkman. 2015. Pain evaluation in dairy cattle. Appl. Anim. Behav. Sci. 171:25-32. https://doi.org/10.1016/j.applanim.2015.08.023.

González, L. A., B. J. Tolkamp, M. P. Coffey, A. Ferret, and I. Kyriazakis. 2008. Changes in feeding behavior as possible indicators for the automatic monitoring of health disorders in dairy cows. J. Dairy Sci. 91:1017-1028. https://doi.org/10.3168/jds.2007-0530.

Henke, J., and W. Erhardt. 2001. Wie entsteht Schmerz? Pages 11-21 in Schmerzmanagement bei Klein- und Heimtieren. 1st ed. J. Henke and W. Erhardt, ed. Enke Verlag, Stuttgart, Germany.

Hodgson, D. S., C. I. Dunlop, P. L. Chapman, and J. A. Smith. 2002. Cardiopulmonary effects of xylazine and acepromazine in pregnant cows in late gestation. Am. J. Vet. Res. 63:1695-1699. https://doi .org/10.2460/ajvr.2002.63.1695.

Hofmann, E. 2006. Hormone und Stoffwechsel. Pages 623-707 in Medizinische Biochemie systematisch. 4th ed. E. Hofmann, ed. UNIMED, Bremen, Germany.

Hökfelt, T., B. Pernow, and J. Wahren. 2001. Substance P: A pioneer amongst neuropeptides. J. Intern. Med. 249:27-40. https://doi .org/10.1046/j.0954-6820.2000.00773.x.

Hsu, W. H., and S. K. Hummel. 1981. Xylazine-induced hyperglycemia in cattle: a possible involvement of a2-adrenergic receptors regulating insulin release. Endocrinology 109:825-829. https://doi.org/10 .1210/endo-109-3-825.

Hudson, C., H. Whay, and J. Huxley. 2008. Recognition and management of pain in cattle. In Pract. 30:126-134. https://doi.org/10 .1136 /inpract.30.3.126.

Hunt, S. P., and P. W. Mantyh. 2001. The molecular dynamics of pain control. Nat. Rev. Neurosci. 2:83-91. https://doi.org/10.1038/ 35053509 .

Huxley, J. N., and H. R. Whay. 2006. Current attitudes of cattle practitioners to pain and the use of analgesics in cattle. Vet. Rec. 159:662-668. https://doi.org/10.1136/vr.159.20.662.

Janowitz, H. 1998. Laparoskopische Reposition und Fixation des nach links verlagerten Labmagens beim Rind. Tierarztl. Prax. (G) $26: 308-313$.

Jawor, P. E., J. M. Huzzey, S. J. LeBlanc, and M. A. G. Von Keyserlingk. 2012. Associations of subclinical hypocalcemia at calving with milk yield, and feeding, drinking, and standing behaviors around parturition in Holstein cows. J. Dairy Sci. 95:1240-1248. https://doi.org/10.3168/jds.2011-4586.

Jorritsma, R., B. Westerlaan, M. P. R. Bierma, and K. Frankena. 2008. Milk yield and survival of Holstein-Friesian dairy cattle after laparoscopic correction of left-displaced abomasum. Vet. Rec. 162:743-746. https://doi.org/10.1136/vr.162.23.743.

Kasimanickam, R., V. Kasimanickam, J. Gold, D. Moore, J. P. Kastelic, D. Pyrdek, and K. Ratzburg. 2019. Injectable or transdermal flunixin meglumine improves pregnancy rates in embryo transfer recipient beef cows without altering returns to estrus. Theriogenology 140:8-17. https://doi.org/10.1016/j.theriogenology.2019.08 .011 .

Löscher, W. 2003. Pharmaka mit Wirkung auf das Zentralnervensystem. Pages 63-124 in Pharmakotherapie bei Haus- und Nutztieren. 7th. W. Löscher, F. R. Ungemach, and R. Kroker, ed. Parey Verlag, Berlin, Germany.

Malhi, M., A. B. Kachiwal, S. A. Soomro, J. A. Gandahi, and S. H. Abro. 2015. Comparison of effects of xylazine, detomidine and medetomidine on heart rate, respiratory rate and blood glucose level in sheep. Pak. J. Agric. Eng. Vet. Sci. 31:93-101.

McMeekan, C. M., K. J. Stafford, D. J. Mellor, R. A. Bruce, R. N. Ward, and N. G. Gregory. 1998. Effects of regional analgesia and/ or a non-steroidal anti-inflammatory analgesic on the acute cortisol response to dehorning in calves. Res. Vet. Sci. 64:147-150. https://doi.org/10.1016/S0034-5288(98)90010-8.

Meyer, H., S. B. R. Kästner, M. Beyerbach, and J. Rehage. 2010. Cardiopulmonary effects of dorsal recumbency and high-volume caudal epidural anaesthesia with lidocaine or xylazine in calves. Vet. J. 186:316-322. https://doi.org/10.1016/j.tvjl.2009.08.020. 
Mohammed, A. A., A. Al-Hozab, and T. Alshaheen. 2018. Effects of diazepam and xylazine on changes of blood oxygen and glucose levels in mice. Adv. Anim. Vet. Sci. 6:121-127. https://doi.org/10 .17582/journal.aavs/2018/6.3.121.127.

Molony, V., and J. E. Kent. 1997. Assessment of acute pain in farm animals using behavioral and physiological measurements. J. Anim. Sci. 75:266-272. https://doi.org/10.2527/1997.751266x.

Mudroň, P., J. Rehage, H. P. Sallmann, M. Höltershinken, and H. Scholz. 2005. Stress response in dairy cows related to different blood glucose. Acta Vet. Brno 74:37-42. https://doi.org/10.2754/ avb200574010037.

Mueller, K. 2011. Diagnosis, treatment and control of left displaced abomasum in cattle. In Pract. 33:470-481. https://doi.org/10 .1136/inp.d6079.

Muir, W. W. III, and C. J. Woolf. 2001. Mechanisms of pain and their therapeutic implications. J. Am. Vet. Med. Assoc. 219:1346-1356. https://doi.org/10.2460/javma.2001.219.1346.

Otto, K. 2001. 5. Schmerztherapie. Pages 51-87 in Schmerztherapie bei Klein-, Heim- und Versuchstieren. K. Otto, ed. Parey, Berlin, Germany.

Pesenhofer, G., R. Palme, R. M. Pesenhofer, and J. Kofler. 2006. Comparison of two methods of fixation during functional claw trimming-walk-in crush versus tilt table-in dairy cows using faecal cortisol metabolite concentrations and daily milk yield as parameters. Wien. Tierärztl. Mschr. 93:288-294.

Rizk, A., S. Herdtweck, H. Meyer, J. Offinger, A. Zaghloul, and J. Rehage. 2012a. Effects of xylazine hydrochloride on hormonal, metabolic, and cardiorespiratory stress responses to lateral recumbency and claw trimming in dairy cows. J. Am. Vet. Med. Assoc. 240:1223-1230. https://doi.org/10.2460/javma.240.10.1223.

Rizk, A., S. Herdtweck, J. Offinger, H. Meyer, A. Zaghloul, and J. Rehage. 2012b. The use of xylazine hydrochloride in an analgesic protocol for claw treatment of lame dairy cows in lateral recumbency on a surgical tipping table. Vet. J. 192:193-198. https://doi .org/10.1016/j.tvjl.2011.05.022.

Rombach, M., A. Münger, J. Niederhauser, K.-H. Südekum, and F. Schori. 2018. Evaluation and validation of an automatic jaw movement recorder (RumiWatch) for ingestive and rumination behaviors of dairy cows during grazing and supplementation. J. Dairy Sci. 101:2463-2475. https://doi.org/10.3168/jds.2016-12305.

Rombach, M., K.-H. Südekum, A. Münger, and F. Schori. 2019. Herbage dry matter intake estimation of grazing dairy cows based on animal, behavioral, environmental, and feed variables. J. Dairy Sci. 102:2985-2999. https://doi.org/10.3168/jds.2018-14834.

Roy, J. P., and M. Rousseau. 2017. Laparoscopic Abomasopexy. Pages 280-289 in Farm Animal Surgery. Vol. 2. D. L. Fubini and N. G. Ducharme, ed. Elsevier, St. Louis, MO.
Siivonen, J., S. Taponen, M. Hovinen, M. Pastell, B. J. Lensink, S. Pyörälä, and L. Hänninen. 2011. Impact of acute clinical mastitis on cow behaviour. Appl. Anim. Behav. Sci. 132:101-106. https:// doi.org/10.1016/j.applanim.2011.04.005.

Snijdelaar, D. G., R. Dirksen, R. Slappendel, and B. J. Crul. 2000. Substance P. Eur. J. Pain 4:121-135. https://doi.org/10.1053/eujp 2000.0171.

Sprecher, D. J., D. E. Hostetler, and J. B. Kaneene. 1997. A lameness scoring system that uses posture and gait to predict dairy cattle reproductive performance. Theriogenology 47:1179-1187. https:// doi.org/10.1016/S0093-691X(97)00098-8.

Stöber, M. 1990. Beruhigung, Niederlegen und Schmerzausschaltung durch Medikamente. Pages 37-74 in Die klinische Untersuchung des Rindes. 3rd ed. G. Dirksen, H.-D. Gründer, and M. Stöber, ed. Paul Parey, Berlin, Germany.

Trent, A. M. 2017. Surgery of the abomasum. Pages 260-280 in Farm Animal Surgery. 2nd ed. S. L. Fubini and N. G. Ducharme, ed. Elsevier, St. Louis, MO.

Tschoner, T., M. Behrendt-Wipperman, A. Rieger, M. Metzner, G. Knubben-Schweizer, F. Reichmann, and M. Feist. 2018. Course of plasma substance $\mathrm{P}$ concentrations during umbilical surgery in calves. Berl. Munch. Tierarztl. Wochenschr. 131:522-528. https:// doi.org/10.2376/0005-9366-17103.

Van Engen, N. K., M. L. Stock, T. Engelken, R. C. Vann, L. W. Wulf, L. A. Karriker, W. D. Busby, J. Lakritz, A. J. Carpenter, B. J. Bradford, W. H. Hsu, C. Wang, and J. F. Coetzee. 2014. Impact of oral meloxicam on circulation physiological biomarkers of stress and inflammation in beef steers after long distance transportation. J. Anim. Sci. 92:498-510. https://doi.org/10.2527/jas.2013-6857.

Whitlock, B. K., E. A. Coffman, J. F. Coetzee, and J. A. Daniel. 2012. Electroejaculation increased vocalization and plasma concentrations of cortisol and progesterone, but not substance $\mathrm{P}$, in beef bulls. Theriogenology 78:737-746. https://doi.org/10.1016/j .theriogenology.2012.03.020.

\section{ORCIDS}

T. S. Tschoner ๑ https://orcid.org/0000-0001-9640-9190

Y. Zablotski $\odot$ https://orcid.org/0000-0001-6928-4089

G. Knubben-Schweizer @ https://orcid.org/0000-0002-0928-5933

M. Feist @ https://orcid.org/0000-0001-9374-9122 